\title{
Las instituciones de educación superior y la responsabilidad social en el marco de la sustentabilidad
}

\author{
Higher Education Institutions and Social Responsibility in the Context of Sustainability
}

\author{
Pedro César Cantú-Martínez' \\ Facultad de Salud Pública y Nutrición \\ Universidad Autónoma de Nuevo León \\ Monterrey, N. L., México \\ cantup@hotmail.com
}

Recibido 28 de enero de 2013 • Corregido 10 de junio de 2013 • Aceptado 19 de junio de 2013

\begin{abstract}
Resumen. El presente artículo de revisión aborda un tema de trascendental importancia para las instituciones de educación superior, como es la responsabilidad social. El enfoque de responsabilidad social retoma un apogeo en el dominio de los debates por la crisis ambiental y por la búsqueda del desarrollo sustentable. Este artículo de revisión expone, en particular, cómo en México, las instituciones de educación superior deben contar con un desarrollo, tanto cualitativo como cuantitativo, muy relevante que trascienda y sea permanente para contextualizar las demandas de nuestra sociedad. Además, se menciona la experiencia de implementación de la responsabilidad social en la Universidad Autónoma de Nuevo León.
\end{abstract}

Palabras claves. Responsabilidad social, sustentabilidad, universidades, México.

Abstract. This review article explores an issue of vital importance to higher education institutions, that is, social responsibility. The social responsibility approach is back on the table of the environmental crisis and sustainable development debates. This review article explains how higher education institutions, particularly in México, should have a permanent highly relevant qualitativequantitative development to contextualize the demands of society. It refers to the experience of the Autonomous University of Nuevo Leon in implementing social responsibility.

Keywords. Social responsibility, sustainability, universities, México.

1 Doctorado en Ciencias Biológicas por la Universidad Autónoma de Nuevo León (UANL), en México. Profesor de la UANL, adscrito a la Facultad de Salud Pública y Nutrición en Monterrey, N.L., México. Participa en el Instituto de Investigaciones Sociales y en el Centro de Investigación y Desarrollo en Ciencias de la Salud de la UANL. Colabora con la Organización Panamericana de la Salud y Comisión de Salud Fronteriza México-Estados Unidos. Miembro del Sistema Nacional de Investigadores-CONACYT: Nivel 1. Miembro del Cuerpo Académico de Salud y Nutrición Poblacional UANL-CA-220 con nivel Consolidado. Su línea de investigación es calidad de vida e indicadores de sustentabilidad ambiental. 
URL: http://www.una.ac.cr/educare

CORREO: educare@una.cr

La historia de la responsabilidad social no cuenta con una fecha cierta de inicio, sin embargo, a fin de marcar algún antecedente, podríamos decir que el ser humano, por obligación, ha de vincularse con otros miembros de la sociedad a la que pertenece y, por esta razón, le corresponde desempeñar una progresión de normas de conducta y actuación, dependiendo del sitio y el período en el que se halle; a estos deberes que cada persona debe practicar con los demás se les denomina responsabilidad social. Así, la representación que las personas tienen sobre el compromiso para con su colectividad social se manifiesta desde la antigua Grecia, en los escritos de Platón, Aristóteles y Cicerón y el régimen romano de derecho y justicia (Camargo, 2007; Rivera y Malaver, 2011).

En la actualidad, la responsabilidad social florece en el concierto internacional en el siglo XX, particularmente en la década de los setentas (Salazar, 2006), teniendo en las instituciones y organizaciones empresariales sus mejores representantes, donde se establecen códigos de conducta internos que sancionan que en el desarrollo e implementación de sus actividades habituales y productivas, tanto internamente como externamente, estas deberán ser sostenibles, sin violentar los derechos sociales de la comunidad y de sus trabajadores, ni provocar un deterioro del medio ambiente.

Esto condujo a confrontar el paradigma económico que en la actualidad se desarrolla con aquel que involucra la inclusión de la responsabilidad social, consiguiendo en esta comparación identificar rasgos muy representativos que los diferencian de quienes los practican, como menciona Salazar (2006). Entre estas diferencias, encontramos que el modelo económico actual se distingue por favorecer una economía de mercado global, encauzada a la especialización con una producción en masa y teniendo en el crecimiento económico su principal propósito; además, promueve la competencia con un rumbo reduccionista de la ciencia que impacta en la sociedad.

Mientras, el modelo económico con responsabilidad social se diferencia en que aplica la premisa de menos dependencia, enfocado en la diversidad con el involucramiento de los diferentes actores sociales, con un sistema productivo que promueve el equilibrio ecológico y justicia social, donde se plasma la cooperación, impulsando el ámbito de orden multidisciplinario en la aplicación de las actividades científicas que favorece la sustentabilidad de nuestra sociedad (Salazar, 2006).

Es así que la responsabilidad social -particularmente en las empresas- encamina sus actividades en cuatro ámbitos de desempeño: cómo es la parte económica, la reglamentaria y legal, la ética y la filantrópica (Soriano, 2011). A esto atañe el objetivo y razonable repartimiento de bienes y servicios, el cumplimiento de los marcos legales que reglamentan su trabajo y desempeño, la incorporación de valores que se concentran en hacer lo correcto y justo $y$, finalmente, en proporcionar apoyos a las comunidades en las cuales están enclavadas.

Hoy, el enfoque de responsabilidad social retoma un apogeo en el dominio de los debates, por la crisis ambiental y por la búsqueda de la consolidación del desarrollo sustentable, los cuales se mancomunan a estándares de desarrollo socioeconómico y a los estilos de vida paralelos 
con estos. Es en este contexto, más y más, instituciones de educación superior (IES) pretenden suscitar y ejercer la responsabilidad social universitaria, ya que las IES no debían permanecer apartadas de la reflexión sobre responsabilidad social, debido a que también se erigen como organizaciones que, mediante sus primordiales y trascendentales objetivos -la formación de recursos humanos, tanto en lo profesional como en lo humanístico, y la generación de nuevos conocimientos a través de la investigación que desarrollan sus académicos-, tienen impactos muy concretos en la sociedad (Domínguez, 2009).

De manera tal, que al concebir a las IES como organismos subsidiarios en nuestra sociedad de la producción y divulgación del conocimiento, y de la formación profesional como sus fundamentales productos es preciso saber, de estas, el razonamiento de la pertinencia, para verificar que los planes, estrategias y objetivos planteados por las IES conciernen a los aspirados y declarados por la sociedad (Díaz y García, 2011; Martínez et al., 2006).

Como resultado de lo anterior, la representación social de las IES que queda impresa en la sociedad se plasma en las funciones que cumplen en el entorno social, a través de la articulación de proyectos que concatenan las prácticas y conocimientos de las IES con los saberes y experiencias del tejido social, y así responder a las variadas y progresivas peticiones o retos de las heterogéneas agrupaciones civiles con las cuales interactúa.

\section{La responsabilidad social y las instituciones de educación superior}

Desgraciadamente, en los albores del siglo XXI, nos hemos percatado de una crisis que conlleva circunstancias de orden mundial y local; que se vuelve cada vez más compleja e impredecible; que perturba todas las facetas de nuestras vidas, tales como las de orden cultural, económico, de salud y las representadas en la calidad ambiental; así como los de valores y el trato con nuestros semejantes (Cantú-Martínez, 2008). En este último aspecto, particularmente, se ha suscitado el cuestionamiento de los valores de nuestra sociedad y de la responsabilidad social que incumbe a las IES, porque estas se han constituido históricamente, en el sitio de cruce del ser humano, la ciencia y la sociedad, y están íntimamente relacionadas con la formación de valores para estimular el desarrollo comunitario y el mejoramiento de la calidad de vida de todo ser humano (Castañeda et al., 2007).

De tal manera que en los círculos académicos, durante los últimos años, se ha discutido el tema de la responsabilidad social, como un aspecto relevante, particularmente porque brinda una dimensión en la cual las IES desarrollan una toma de conciencia de carácter holista, que involucra a la propia organización de las instituciones y el impacto de estas en su entorno social. En este, se observa una capacidad de convocatoria para amalgamar la participación de varios actores sociales y actividades que exhiben variados matices de orden filosófico, social y económico (Castañeda et al., 2007). Amén de procurar en todos los miembros de su estructura orgánica -académicos, estudiantes y trabajadores- un comportamiento ético, que impulsa una concreción de la voluntad de querer hacer todas las acciones con eficacia y capacidad, para 
URL: http://www.una.ac.cr/educare

CORREO: educare@una.cr

responder así a las exigencias y necesidades que plantean actualmente las colectividades y agrupaciones sociales (Vallaeys, 2006). Soriano (2011) manifiesta que en Iberoamérica, en los últimos años han existido trabajos precursores que se han enfocado a elucidar conceptualmente la orientación de responsabilidad social en las IES, entre estos antecedentes advierte del:

... Proyecto Universidad: Construye País (2002) promovido por un grupo de universidades chilenas; los trabajos realizados por la Asociación de Universidades confiadas a la Compañía de Jesús en América Latina, agrupadas en la AUSJAL; el desarrollo del Curso Internacional Virtual ¿Cómo enseñar ética, Capital Social y Desarrollo en la Universidad?, preparado por François Vallaeys y promovido por el BID y el Portal Educativo de la OEA desde el año 2004, así como la actividad impulsada por el Banco Interamericano de Desarrollo con el Programa Red Universitaria de Ética y Desarrollo Social ... (p. 4)

Sin duda, la responsabilidad social está coligada a las actividades inherentes que las IES ejercen para la búsqueda de la consecución de un desarrollo sustentable, tomando en cuenta que estas tienen como fin último formar ciudadanos con principios y responsabilidades, y con una alta sensibilidad para avocarse a la resolución de los problemas que atañen en su entorno medioambiental y social (Rendueles, 2010). Estas actividades, como indica Castañeda et al. (2007), están asociadas a la iniciativa de la Secretaria General de las Naciones Unidas en la concreción del Pacto Global 1999/2000, el cual está destinado a la práctica y comunicación de experiencias -con el propósito de mejorar los estándares de trabajo y de disminuir los efectos negativos al medio ambiente- asimismo con la participación voluntaria de los protagonistas implicados en el marco de los derechos humanos.

Así, entre las definiciones más acreditadas según Rendueles (2010, p. 34) se encuentra la mencionada por el World Business Council for Sustainable Development, que subraya: "es el compromiso que asume una empresa para contribuir al desarrollo económico sostenible por medio de colaboración con sus empleados, sus familias, la comunidad local y la sociedad, con el objeto de mejorar la calidad de vida". Y la forma de expresión bajo las cuales las IES traducen operativamente este concepto es a través de acciones como la docencia, la investigación, la gestión, la proyección y extensión universitaria, y la innovación. Acciones con las cuales se accede a la implementación de programas de orden socioambiental, así como a la incorporación de currículos académicos y actualización del profesorado en materia de sustentabilidad, de manera que estimulen el interés por innovar, mejorar y aprender (Núñez y Alonso, 2009; Pardo, 2011; Rendueles, 2010).

Al introducir estos cambios en el quehacer de las IES se incide en la concreción de una cultura y edificación de un conocimiento científico-humanístico de respeto ético social al entorno socio-ambiental. Y como menciona Lucchesi (2011, p. 28): "Se espera que al desempeñar su responsabilidad social, ella sea el gran instrumento de cohesión social. . . beneficiando a la 
sociedad". Esto incurre positivamente, al observar la instauración de asociaciones estudiantiles y grupos de voluntarios organizados -supervisados por profesores e investigadores en algunos casos- que desarrollan habilidades y un proceder actuante en los estudiantes universitarios en esta materia, o bien en la instauración de programas universitarios con un alto contenido humanista (Pardo, 2011). Rendueles (2010, p. 37), comentando a Cavero, señala que la responsabilidad social universitaria refiere a ". . .un compromiso moral irrenunciable que, a la par que genera nuevo conocimiento relevante para la solución de los problemas sociales, permite la aplicación directa del saber científico y tecnológico, así como una formación profesional más humanitaria".

Para aspirar a una responsabilidad social universitaria, se requiere de un enfoque holístico, como ya mencionamos, que permita articular las diferentes partes que constituyen las IES en un solo proyecto de carácter social, con un alto contenido ético y que promueva un desarrollo equitativo y sustentable (Ayala, 2011). Para la implementación de una reforma organizacional que conlleve a una responsabilidad social en las IES, incumbirían cuatro frentes de acción de manera organizacional, según Ayala (2011):

1. Gestión interna: esta línea de acción refiere a aspectos de transformación interna que conlleven a la identificación de una comunidad universitaria basada en la democracia, equidad, transparencia y de impulso a un desarrollo sustentable.

2. Docencia: este rasgo involucra acciones de capacitación a la planta académica con un matiz de responsabilidad social. Y, además, promover el aprendizaje, sustentado en proyectos de carácter social y aplicado a la resolución de problemas.

3. Investigación: promover una agenda de investigación que vincule a los investigadores y docentes en proyectos de investigación interdisciplinarios que resuelvan problemas, tanto urbanos como rurales, que manifiesten la colectividad social.

4. Proyección social: tratar de efectuar proyectos de desarrollo que puedan ser el origen de investigaciones aplicadas y de recursos didácticos para la comunidad universitaria, que permita al estudiantado un aprendizaje basado en evidencias.

De tal manera que, de manifestarse y alcanzarse las metas trazadas en estas cuatro acciones, se lograría tener un alto impacto en la formación profesional y ciudadana del estudiantado y en la comunidad que rodea a las IES, desde los otros ángulos de orden educativo, cognitivo y epistemológico, dejando atrás aquellos modelos preexistentes de las IES, como el elitista y abierto (Gaete, 2012).

Esta transición puede ser progresiva, recorriendo el modelo universitario elitista -en un primer momento- cuyos objetivos se centran solamente en la formación profesional e investigación básica, donde sus características principales la convierten en sitios de orden 
URL: http://www.una.ac.cr/educare

CORREO: educare@una.cr

minoritario, selectivos y apartados del conglomerado social; pasando -en una segunda instancia- por el modelo abierto, cuyas metas se concentran en el desarrollo de investigación aplicada, transferencia de conocimiento y vinculación de la investigación con el desarrollo tecnológico y la innovación, que permite una apertura a los grupos sociales más potentados en el contexto económico y político; y así arribar, posteriormente -en un tercera etapa-, al modelo universitario socialmente responsable, cuyos rasgos más distintivos son el liderazgo social, que fortalece el aprendizaje-servicio, suscita una educación para la vida, favorece la cooperación para el desarrollo, impulsa el voluntariado universitario y la sustentabilidad, elementos que se insertan en la procuración de una sociedad del conocimiento, donde todos los actores tienen acceso a una educación superior con un alto compromiso social (Gaete, 2012).

No obstante, en contraparte, existen conflictos y escollos que involucran imponer la práctica de la responsabilidad social empresarial a ultranza en las IES -sin considerar esta gradual transformación- particularmente cuando no persiguen los mismos intereses que promueven y establecen las empresas, por lo tanto, señalan: ". . . la propia responsabilidad queda sometida al criterio de la utilidad y ésta es una medida a la que es difícil ponerle un límite preciso en una institución universitaria [. . .] entendida en este caso en términos estrictamente económicos, donde lo útil se identifica con lo económicamente rentable ... " (De la Cruz y Sasia, citado por Gaete, 2012, p. 131).

\section{Premisas y situación de las instituciones de educación superior en México}

En la actualidad, la sociedad en México enfrenta desafíos que trazan el futuro de Siglo XXI, mediante derroteros de diferente índole como son: socioeconómico, político y cultural; donde la estructura de educación superior, constituida por las IES de las 32 entidades federativas, deberán contar con un desarrollo tanto cualitativo como cuantitativo muy relevante, que trascienda y sea permanente para contextualizar las demandas de nuestra sociedad y responda, además, al contexto del cambiante entorno internacional. Para esto sitúa la "visión" del sistema de educación superior en México al año 2020 en lo siguiente (Asociación Nacional de Universidades e Instituciones de Educación Superior [ANUIES], 2000):

En el año 2020, gracias al compromiso efectivo del gobierno federal, de los gobiernos de las 32 entidades federativas y sus municipios, de los poderes legislativos y de la sociedad civil en su conjunto, las instituciones de educación superior de México integran un vigoroso sistema de educación superior, que forma profesionales e investigadores de alto nivel, genera y aplica conocimientos, extiende y preserva la cultura, tareas que realiza con calidad, pertinencia, equidad y cantidad equiparables con los estándares internacionales, gracias a lo cual la educación superior contribuye de manera fundamental a que los mexicanos disfruten de paz y prosperidad en un marco de libertad, democracia, justicia y solidaridad. (p. 150) 
En este sentido, el punto de vista de la formación y educación universitaria en México -de acuerdo con ANUIES (2000) - la cual está constituida por un sistema 1,250 IES, se sostiene en ocho principios que involucran la calidad e innovación; la congruencia con su naturaleza académica; la pertinencia en relación con las necesidades del país; la equidad, el humanismo y el compromiso con la construcción de una sociedad mejor; la autonomía responsable, y las estructuras de gobierno y operación ejemplares. De estos principios orientadores, cuatro despliegan en su contenido un alto compromiso de una praxis social, en especial vinculado al quehacer de las instituciones de educación superior mexicanas con la sociedad.

La primera refiere a la "pertinencia" en relación con las necesidades del país, en la cual, se expresa que las instituciones de educación superior asuman un papel destacado en la caracterización y resolución de necesidades, en el marco de una visión de desarrollo sustentable del país a largo plazo.

En segundo término contamos con la "equidad", con lo cual se busca otorgar apoyo diferencial a instituciones y personas principalmente necesitadas, resueltas para superar su rezago y, así, situarse en condiciones de mayores niveles de calidad.

El tercer aspecto refiere al "humanismo", en el cual las IES se apropian de conceptos como paz, libertad, democracia, justicia, igualdad, derechos humanos y solidaridad, que orientan el quehacer educativo para la formación completa y exhaustiva de profesionales que se manifiesten en ciudadanos comprometidos, participativos y solidarios.

El cuarto y último de los preceptos es el "compromiso con la construcción de una sociedad mejor". Este principio refiere al quehacer de las instituciones de educación superior y en él se plasma su papel fundamental para contribuir a que México llegue a ser una sociedad más acorde, con valores como la calidad, pertinencia y equidad social; que permitan "... hacer de la educación, el conocimiento, la información, la cultura y el progreso científico y tecnológico, los medios para reducir la desigualdad, incrementar el bienestar colectivo sobre bases sustentables y dinamizar los factores esenciales de la competitividad social y económica. . ." (ANUIES, 2012, p. 9). Con lo anterior, se pretende en el marco de las IES en México, contribuir al desarrollo y sustentabilidad social mediante las actividades de sus egresados, o bien, integrados al mercado laboral, y finalmente como instituciones hacedoras de nuevos conocimientos, que orientan los procesos decisorios en materia de políticas públicas.

Sin embargo, también en el concierto nacional, las IES, simultáneamente a la búsqueda de cumplir con lo antes mencionado y asumir su responsabilidad social, todavía tiene que afrontar la insuficiencia de recursos económicos para sufragar sus labores ante la falta de los participaciones presupuestarias del Estado hacia las universidades públicas, donde ". . . la tendencia real de la inversión del gasto federal en educación superior, en proporción al Producto Interno Bruto, es hacia la baja del 2009 a la fecha. En el 2011 se invirtió el 0.65\%, y. . . en el 2012 . . . del 0.62\%; cuando lo deseable sigue siendo invertir por lo menos el 1\%", según advirtió el Mtro. Tonatiuh Bravo Padilla, Rector del Centro Universitario de Ciencias Económicas y Administrativas de la Universidad de Guadalajara, citado por López (2011, p. 1). Esta situación 
URL: http://www.una.ac.cr/educare

CORREO: educare@una.cr

también es ratificada por el Presidente de la Academia Mexicana de las Ciencias, el Dr. Arturo Menchaca Rocha, en su lacónica declaración al señalar: “. . . que es una histórica falta de visión del país" (Zapata, 2011, párr. 6).

Lo anterior ha conllevado a las IES en México a una disyuntiva necesaria, que es alinear sus gestiones y quehaceres a la búsqueda de autofinanciamiento, mediante la venta de servicios:

... incorporando una serie de técnicas y modelos propios de las empresas, tales como la planificación estratégica, indicadores de gestión y cuadro de mando integral, gestión por competencias, criterios de rentabilidad económica para evaluar sus proyectos, estrategias de marketing, entre otras importantes herramientas y modelos de gestión, funcionando de esta forma en muchas ocasiones casi como una verdadera empresa. (Gaete, 2012, pp. 5-6)

Esto pone al descubierto la posibilidad que las IES en México puedan dejar fuera de sus prioridades y trabajo universitario a muchos actores considerados como vulnerables; en esta circunstancia, se puede gestar, como señala Gaete (2012, p. 6): “. . . la 'mercantilización de la educación superior' aparece como una fantasmal sombra que atenta contra la credibilidad e imagen social de las universidades públicas. . ."; en este sentido es plausible el gran esfuerzo que realizan las IES en el país por no perder de vista este objetivo de responsabilidad social universitaria sustentado en el discurso, y que permite satisfacer y resolver -aunque frugalmente con el financiamiento que se les otorga- los problemas y requerimientos de la sociedad en las que se hallan enclavadas.

\section{La Universidad Autónoma de Nuevo León y la responsabilidad social}

Boelen (2009, pp. 200-201) menciona: "Para ser socialmente responsable, una institución educativa debe cuestionarse si sus 'productos' (graduados, modelos de servicio o hallazgos de investigación) son de la mayor utilidad para el interés público. ..." Al cuestionarse su razón de ser y el impacto final de su actuación es cuando una institución asume un elevado nivel de responsabilidad social". En este orden de ideas, y haciendo un tamizaje de los retos que se ostentan hoy, las IES -en términos de la responsabilidad social universitaria- enfocan su misión social en construir procesos internos y entramados de relaciones sociales que impulsen políticas públicas para favorecer la creación de una cultura más humana, el crecimiento económico en sus entornos y con un principio de justicia y equidad social.

En este apartado se muestran algunas de las características actuales de la implementación de la responsabilidad social universitaria en la Universidad Autónoma de Nuevo León (UANL), con el propósito de reflexionar sobre el avance en esta materia y poder aquilatar las acciones emprendidas, pero sobre todo para identificar nuestras áreas de oportunidad y así marcar la 
pauta de hacia dónde debemos dirigir nuestras fortalezas para mejorar como una institución responsable socialmente.

La Universidad Autónoma de Nuevo León (UANL) se encuentra situada en el Estado de Nuevo León en México, en la región noreste del país. Cuenta con una dilatada y variada oferta educativa que corresponde a los campos estratégicos y más trascendentales del conocimiento. En el periodo de agosto a diciembre del 2011 contó con una población escolar de 141,971 estudiantes, los cuales se encuentran distribuidos en los diferentes niveles que se ofertan, cuenta además con una planta académica de tiempo completo de 2,968 profesores (UANL, 2011a). La UANL en los últimos 20 años ha respaldado su progreso y avance en la adopción de disposiciones traducidas en procedimientos de planeación bidireccional, las cuales le han concedido reconocer y examinar los retos que afronta la institución en el desempeño de sus funciones, así como de los medios para erigir y efectuar pertinentemente las acciones para abordarlos. Para esto ha elaborado el documento rector denominado Visión 2020 UANL, el cual sirve de contexto orientador para la toma de decisiones oportunas en el ámbito de la responsabilidad social (UANL, 2011b).

En este orden de ideas, la UANL cuenta, entre las actividades que constituyen su misión, con la de concebir conocimiento social, científico y humanista, como una función que le faculta para otorgar atención adecuada y eficaz a las disímiles problemáticas de carácter social; para ello, promueve valores como la solidaridad, la honestidad, la equidad, respeto a la naturaleza y a la vida de los demás, los cuales se convierten en los peldaños para realizar una gestión socialmente responsable. Los valores antes citados se conjugan con los atributos institucionales que posee la UANL y que propugnan su desarrollo y cumplimiento, entre los que tenemos la autonomía, el espíritu crítico, el pensamiento analítico, el humanismo, la pertinencia, el liderazgo, el trabajo multi, inter y transdisciplinario y, finalmente, la responsabilidad social universitaria.

Esta última, la responsabilidad social universitaria, ha demandado, en la UANL, coherencia en todos los ámbitos del quehacer institucional, lo que representa una alta solidez entre las actividades de los universitarios, los valores y el discurso. Alude igualmente a la importancia de apoderarse de las responsabilidades que le confiere la sociedad, y ha creado diferentes programas establecidos como prioritarios para este fin, entre los que encontramos la "Gestión institucional responsable", el cual cuenta con 29 directrices que guían su articulación, entre las que destacamos:

1. Participación de la universidad en foros y eventos especializados organizados por los tres órdenes de gobierno, para que sus iniciativas y opiniones sean consideradas.

2. Participación de la universidad en la formulación e implementación de políticas públicas para el desarrollo.

3. Establecimiento de redes sociales de responsabilidad social universitaria.

4. Vinculación de la función de extensión con la formación, y la generación y aplicación del conocimiento. 
URL: http://www.una.ac.cr/educare

CORREO: educare@una.cr

Es este aspecto, en la UANL existen diferentes expresiones de responsabilidad social universitaria documentada, las cuales se vinculan con el desarrollo sustentable, en el marco de las distintas dimensiones que lo constituyen, entre ellas podemos mencionar algunas (Ancer, 2010; UANL, 2012):

a) El programa universitario de salud: Tiene entre sus objetivos la formación universitaria con enfoque social con el firme compromiso con su comunidad, así como su relación con el medio ambiente; en él colaboran catedráticos, estudiantes e investigadores de las Facultades de Medicina, Psicología, Enfermería, Odontología, Trabajo Social, Salud Pública y Nutrición, así como de Ciencias de la Comunicación. Este programa opera en la UANL, a través del Centro Universitario de Salud, instancia cuya característica distintiva es articular interinstitucionalmente y de forma multidisciplinaria los esfuerzos que, en materia de salud, realiza la UANL y la Secretaría de Salud en Nuevo León, el Instituto Mexicano del Seguro Social y los Municipios de Apodaca y Guadalupe.

b) El servicio social comunitario: Se establece de una forma armónica con organismos públicos o privados que participan de propósitos similares a los de la UANL, y con ello garantiza el oportuno y eficiente otorgamiento de un mejor escenario social en la comunidad, mediante la inserción de las prácticas profesionales de los estudiantes.

c) Los proyectos de investigación: Realizados por los investigadores, los cuales son financiados por diferentes fuentes de carácter gubernamental y no gubernamental, que se ligan a los breviarios internacionales de investigación para el estudio y resolución de problemas globales que nos aquejan, como las enfermedades emergentes, el cambio climático, la pobreza y exclusión social, el menoscabo de la democracia y lo que atañe a los derechos humanos, por citar algunos rubros; con lo anterior, se patentiza que la investigación y el desarrollo tecnológico en la UANL son claves para transitar por una senda con responsabilidad social, por lo cual se ha erigido una agenda de investigación sobre aspectos que atañen al desarrollo sustentable, que se sostiene en las premisas de respeto incondicional a la vida y atiende, constantemente, las demandas de las personas y del cuidado de su integridad.

d) La conformación de un observatorio de la sustentabilidad de Nuevo León: primera iniciativa de investigación y desarrollo, que, en México, cuenta con apoyo del Consejo Nacional de Ciencia y Tecnología y el Instituto de Investigaciones Sociales. Fue concebido por un grupo de académicos universitarios, cuyo objetivo es evaluar y poner a disposición de la colectividad social una serie de información emanada de diferentes fuentes gubernamentales y no gubernamentales, para monitorear el progreso que se lleva por la senda de la sustentabilidad en el Estado de Nuevo León.

e) La convocatoria al programa "Tigres al rescate": Constituye una actividad que realiza la comunidad de estudiantes, quienes, organizadamente, suman esfuerzos para recaudar fondos económicos en apoyo a instituciones u organizaciones de beneficencia social. 
f) La "Brigada demos vida a su sonrisa": Actividad estudiantil, que brinda apoyo de asistencia social y humanitaria a grupos vulnerables como niños y adultos de comunidades remotas en el Estado de Nuevo León, en el ámbito de la salud, vivienda, entre otros aspectos a destacar.

g) La "Alianza por la sustentabilidad": Actividad que se suma a los esfuerzos gubernamentales de carácter estatal, aportando durante el año 2011, un donativo 200 mil plántulas que serán empleadas a la reforestación de zonas boscosas y rurales en el Estado de Nuevo León; además, durante este mismo año se firmó un convenio de colaboración con los Servicios de agua y drenaje de Monterrey, el cual le permitirá contar con agua tratada para el riego de los jardines de sus campus universitarios, y representará un ahorro de 800 mil litros diarios de agua potable.

h) El establecimiento de los "Comités para la sustentabilidad": Constituidos en el año 2012 en cada dependencia de la UANL, y en la que participan un académico, un trabajador administrativo y un estudiante, esto es, 210 responsables con la tarea de vigilar el uso adecuado de los recursos de energía, agua, gas, manejo de residuos no peligrosos y peligrosos, como también el uso de los espacios verdes.

i) La "Universidad para los adultos mayores": Ejecuta acciones de enseñanza, de asistencia y de articulación para extender la formación académica de personas adultas mayores de 55 años, con el propósito de mejorar su calidad de vida, crecimiento personal y particularmente su reintegración social.

Es así como el fomento de la responsabilidad social y la sustentabilidad universitaria en la UANL se ha desarrollado impulsando su aplicación en relación con los entornos locales y, más puntual, en el espacio del propio campus universitario; con esto ha distinguido de manera sobresaliente, el seguimiento a los compromisos precisados como comunidad universitaria, en los ámbitos de carácter ambiental, social, cultural y económico.

El esfuerzo y empeño antes señalado en la UANL le ha hecho merecedora, el 14 de noviembre del 2012, del Certificado de Responsabilidad Social Empresarial (WORLDCOBCSR:2011.1), que le concedió la Confederación Mundial de Negocios -con sede en la ciudad texana de Houston, Estados Unidos- por su elevado compromiso social con la comunidad y por incidir en aspectos como el establecimiento de una política de mejora continua, la inserción de valores éticos, así como de actividades realizadas en favor de la sustentabilidad (Loredo, 2012). Este acontecimiento posiciona a la UANL en el concierto nacional, como la primera IES, en alcanzar este prestigioso reconocimiento internacional y se suma al distinguido conjunto de doce organizaciones en México, con una comprobada actitud institucional de responsabilidad social. 
URL: http://www.una.ac.cr/educare

CORREO: educare@una.cr

\section{Conclusiones}

Durante mucho tiempo las IES fueron contempladas como el sitio donde se desarrolla la catarsis del quehacer científico y técnico; y eran únicamente encargadas de la difusión del conocimiento científico, un tanto aisladas del escenario socio-ambiental existente en su entorno. Sin embargo, los eventos surgidos en los últimos años en las esferas culturales y socioeconómicas, que atañen un orden de carácter global, han establecido que las IES se ajusten al contexto de la realidad, lo que pone a prueba, hoy en día, sus estructuras e instrumentos de control interno para relacionar su misión y el cumplimiento de sus funciones con las necesidades claves del colectivo social, en el marco de la responsabilidad social. Actualmente se ha superado este aspecto a través de favorecer la movilidad del conocimiento y aprendizaje, tanto dentro como fuera del sistema formativo.

Reconociendo lo anterior, la responsabilidad social recientemente principia a procurarse en el espacio de las IES en México y, por lo tanto, el reto que deberán confrontarse, por parte de las IES, será el erigirse en la vía de acceso para transitar de la sociedad de la información a la sociedad del conocimiento, donde permita constituir un espacio de creación arraigado y sistémico, primordial para la vinculación de un nuevo proyecto social que pretenda un desarrollo autosostenido y más equitativo. Esencialmente, al asumir con responsabilidad su función central de formación de nuevos profesionistas y de generar conocimiento con un alto contenido social, cuyo gesto se ajuste a las exigencias de la verdadera responsabilidad social universitaria, que hoy exige la sociedad en general, pero además fincando los contenidos curriculares que permitan la construcción de la misma y el apropiamiento por sus egresados. Pero también adoptando razonamientos de sustentabilidad, ante el impacto que estimulan al entorno, por el desarrollo de sus actuaciones y en la vida diaria de los campus.

Es en éste escenario, las IES en México han asentado este compromiso a través de la inserción de valores y principios que se plasman en su misión y visión institucional, y que se declara explícitamente en sus proyectos de desarrollo institucional; pero también, algunas otras IES han logrado transferir estos valores y principios en actividades en su entorno socioambiental $y$, actualmente, se encuentran evaluando los impactos de sus actuaciones.

Por último, las IES en México están respondiendo a este reto que se constituye en un tipo nuevo de liderazgo. Al margen de la calidad académica e investigadora que pueda erigirse en ellas, hoy la actuación socialmente responsable es un aspecto que se establece a través de la ANUIES como un componente importante de notoriedad y reconocimiento social, que deriva en una prerrogativa competitiva en el mercado de la educación superior y se convierte, además, en un instrumento de certificación y legitimación de los trabajos de las IES hacia la sociedad. 


\section{Referencias}

Ancer, J. (julio-septiembre, 2010). Investigación con responsabilidad social [Editorial]. Ciencia UANL, 13(3), 225.

Asociación Nacional de Universidades e Instituciones de Educación Superior (ANUIES). (2000). La educación superior en el siglo XXI. Líneas estratégicas de desarrollo. Una propuesta de la ANUIES. México: Autor.

Asociación Nacional de Universidades e Instituciones de Educación Superior (ANUIES). (2012). Inclusión con responsabilidad social. Una nueva generación de políticas de educación superior. México: Autor. Recuperado de http://www.academica.mx/sites/default/files/inclusion responsabilidad social.pdf

Ayala, M. O. (septiembre-diciembre, 2011). Responsabilidad social universitaria. Realidad y Reflexiones, 11(33), 29-37. Recuperado de http://redicces.org.sv/jspui/bitstream/10972/91/1/ Responsabilidad\%20social\%20universitaria.pdf

Boelen, C. (diciembre, 2009). Responsabilidad social y excelencia. Educación Médica, 12(4), 199205. Recuperado de http://scielo.isciii.es/pdf/edu/v12n4/editorial.pdf

Camargo, R. (2007). Lo social desde el concepto de ilusión en Platón, Aristóteles, Machiavelo y Bacon. Cinta de Moebio, 28, 29-38. Recuperado de http://www.facso.uchile.cl/publicaciones/ moebio/28/camargo.pdf

Cantú-Martínez, P. C. (2008). Desarrollo sustentable. Conceptos y reflexiones. (Colección Tendencias Científicas). Monterrey: Editorial Universidad Autónoma de Nuevo León.

Castañeda, G., Ruiz, M., Viloria, O., Castañeda, R. y Quevedo, Y. (noviembre, 2007). El rol de las universidades en el contexto de la responsabilidad social empresarial. Revista Negotium, 3(8), 100-132. Recuperado de http://www.revistanegotium.org.ve/pdf/8/Art4.pdf

Díaz, I. y García, M. (2011). Más allá del paradigma de la alfabetización. La adquisición de cultura científica como reto educativo. Formación Universitaria, 4(2), 3-14. doi: 10.4067/S071850062011000200002

Domínguez, M. J. (2009). Responsabilidad social universitaria. Humanismo y Trabajo Social, 8, 37-67. Recuperado de https://buleria.unileon.es/bitstream/handle/10612/1498/Hum8 art1. pdf?sequence $=1$

Gaete, R. (2012). Responsabilidad social universitaria: Una nueva mirada a la relación de la universidad con la sociedad desde la perspectiva de las partes interesadas. Un estudio de caso. (Tesis doctoral). Universidad de Valladolid, Facultad de Educación y Trabajo Social. Valladolid, España. Recuperado de http://uvadoc.uva.es/bitstream/10324/923/1/TESIS148120417.pdf 
URL: http://www.una.ac.cr/educare

CORREO: educare@una.cr

López, L. (2011). Sigue siendo bajo para 2012 el presupuesto para la educación superior en México. Guadalajara: Difusión CUSEA. Recuperado de http://www.cucea.udg.mx/?q=noticia/siguesiendo-bajo-para-2012-el-presupuesto-para-la-educaci-n-superior-en-m-xico

Loredo, E. (14 de noviembre de 2012). Organismo global reconoce a la UANL. UANL-Noticias Institucional. Recuperado de http://www.uanl.mx/noticias/institucional/organismo-globalreconoce-la-uanl.html

Lucchesi, M. A. S. (2011). La Universidad Internacional en América Latina: Un nuevo paradigma para el Siglo XXI. Formación Universitaria, 4(1), 25-36. Doi: 10.4067/S0718-50062011000100005

Martínez, C., Mavarez, R., Rojas, L., Rodríguez, J. y Carvallo, B. (junio, 2006). La responsabilidad social como instrumento para fortalecer la vinculación universidad-entorno social. Trabajo presentado en el I Congreso Iberoamericano de Ciencia, Tecnología Sociedad e Innovación CTS+I. México. OEI, AECI, UNAM, IPN, UAM, Academia Mexicana de Ciencias y la Academia de Ingenieros.

Nuñez, M. y Alonso, I. (2009). La responsabilidad social en el mapa estratégico de las universidades públicas. Pecvnia, 9, 157-180. Recuperado de http://pecvnia.unileon.es/ pecvnia09/09 157 180.pdf

Pardo, M. (2011). La universidad: ¿Cuál es su papel en el desarrollo sostenible? Madrid: Universidad Carlos III de Madrid / CEICAG. Recuperado de http://www.uc3m.es/portal/page/portal/ grupos investigacion/sociologia cambio climatico/Universidad\%20y\%20desarrollo\%20 sostenible.pdf

Rendueles, M. (2010). Mercadeo social, responsabilidad social y balance social: Conceptos a desarrollar por instituciones universitarias. TELOS. Revista de Estudios Interdisciplinarios en Ciencias Sociales, 12(1), 29-42. Recuperado de http://www.publicaciones.urbe.edu/index. php/telos/issue/view/221/showToc

Rivera, H. A. y Malaver, M. N. (julio, 2011). La organización: Los stakeholders y la responsabilidad social. (Serie Documentos de Investigación). Universidad Colegio Mayor de Nuestra Señora Del Rosario, 97, 1-34.

Salazar, J. de J. (2006). La responsabilidad social de las empresas. Teoría y evidencia en México. (Tesis doctoral inédita). Universidad Autónoma de Nuevo León, Instituto de Investigaciones Sociales. Monterrey, N. L., México.

Soriano, O. (14 de junio de 2011). Responsabilidad social universitaria. Trabajo presentad en el I Foro Internacional de Educación Superior: Educación Superior, Estado y Desarrollo. Tegucigalpa, Universidad Nacional Autónoma de Honduras y Banco Centroamericano de Integración Económica. Recuperado de https:/www.unah.edu.hn/uploaded/content/ category/1545153038.pdf

UANL. (2011a). Informe de actividades del Sr. Rector Jesús Ancer Rodríguez. Monterrey: Autor. 
URL: http://www.una.ac.cr/educare CORREO: educare@una.cr

UANL. (2011b). Visión 2020 UANL. Monterrey: Autor

UANL. (2012). Informe de actividades del Sr. Rector Jesús Ancer Rodríguez. Monterrey: Autor.

Vallaeys, F. (2006). La responsabilidad social de la universidad. Palestra. Recuperado de http:// aiesmin.unsl.edu.ar/responsabilidad.pdf

Zapata, J. J. (24 de febrero de 2011). Tenemos que invertir en educación: Arturo Menchaca. UANL-Noticias: Académico. Recuperado de http://www.uanl.mx/noticias/ academico/\%E2\%80\%9Ctenemos-que-invertir-en-educacion\%E2\%80\%9D-arturomenchaca.html

\section{Cómo citar este artículo en APA:}

Cantú-Martínez, P. C. (2013). Las instituciones de educación superior y la responsabilidad social en el marco de la sustentabilidad. Revista Electrónica Educare, 17(3), 41-55. Recuperado de http://www.revistas.una.ac.cr/index.php/EDUCARE/issue/current

Nota: Para citar este artículo en otros sistemas puede consultar el hipervínculo "Como citar el artículo" en la barra derecha de nuestro sitio web:

http://www.revistas.una.ac.cr/index.php/EDUCARE/index 